\title{
Commentary
}

\section{Advancing health equity to improve health: the time is now}

\author{
B. Jackson, PhD (1); P. Huston, MD, MPH (2)
}

\begin{abstract}
Health inequities, or avoidable inequalities in health between groups of people, are increasingly recognized and tackled to improve public health. Canada's interest in health inequities goes back over 40 years, with the landmark 1974 Lalonde report, and continues with the 2011 Rio Political Declaration on Social Determinants of Health, which affirmed a global political commitment to implementing a social determinants of health approach to reducing health inequities. Research in this area includes documenting and tracking health inequalities, exploring their multidimensional causes, and developing and evaluating ways to address them. Inequalities can be observed in who is vulnerable to infectious and chronic diseases, the impact of health promotion and disease prevention efforts, how disease progresses, and the outcomes of treatment. Many programs, policies and projects with potential impacts on health equity and determinants of health have been implemented across Canada. Recent theoretical and methodological advances in the areas of implementation science and population health intervention research have strengthened our capacity to develop effective interventions.
\end{abstract}

With the launch of a new health equity series this month, the journals Canada Communicable Disease Report and Health Promotion and Chronic Disease Prevention in Canada will continue to reflect and foster analysis of social determinants of health and focus on intervention studies that advance health equity.

\section{Introduction}

The World Health Organization (WHO) defines health inequity as "avoidable inequalities in health between groups of people within and between countries." Not only is health equity an international and domestic concern, it is a fertile field of research and practice across disciplines, sectors and jurisdictions.

While a majority of Canadians enjoy good health, health inequalities persist and, in some areas, are growing. ${ }^{2,3}$ But much can be done to address this. The objective of this introductory commentary is to review some key milestones in domestic and global health equity work, highlight recent advances and recommended actions in Canada, and assert that new evidence on inequalities and interventions can create promising opportunities for collaborative action across sectors to address health equity and improve health.

\section{Key Milestones}

\section{Early days}

The landmark 1974 Lalonde report, "A New Perspective on the Health of Canadians," asserted that the quantity, quality and arrangement of acute health care systems explain only a fraction of why a population is healthy. ${ }^{4}$ The "health fields" identified in the report (biology, individual choices, physical and social environments, and health care) were an early expression of what would become known as the "social determinants of health." The Lalonde report was quickly followed by other key policy documents: the WHO Alma-Ata Declaration on Primary Health Care in $1978^{5}$; the Canadian Epp
Report, Achieving Health for All, ${ }^{6}$ and the WHO "Ottawa Charter for Health Promotion" in $1986 .{ }^{7}$ Later key publications such as Why Are Some People Healthy and Others Not? The Determinants of Health of Populations ${ }^{8}$ and Strategies for Population Health: Investing in the Health of Canadians in $1994^{9}$ signalled a reframing of public health into a "population health" perspective, informed by social determinants of health.

\section{Calls for global action}

WHO Commission on Social Determinants of Health

In 2008, the WHO Commission on Social Determinants of Health made a clear link between the social determinants of health and health equity in its report Closing the Gap in a Generation: Health Equity Through Action on the Social Determinants of Health. ${ }^{10}$ The Commission stated: "inequities in health, avoidable health inequalities, arise because of the circumstances in which people grow, live, work, and age, and the systems put in place to deal with illness. The conditions in which people live and die are, in turn, shaped by political, social, and economic forces.."10 The Commission's three overarching recommendations and related principles of action focus on:

- improving daily living conditions;

- tackling the inequitable distribution of power, money and resources-the structural drivers of the conditions of daily life; and

- measuring the extent of health inequities and assessing the health equity impact of policy and other actions. ${ }^{10}$

This renewed call for global action has supported efforts in Canada in the public health sector and across sectors. Reflecting

Author references:

1. Social Determinants and Science Integration Directorate, Health Promotion and Chronic Disease Prevention Branch, Public Health Agency of Canada, Ottawa, Ontario, Canada 2. Assistant Deputy Minister's Office, Infectious Diseases Prevention and Control Branch, Public Health Agency of Canada, Ottawa, Ontario, Canada

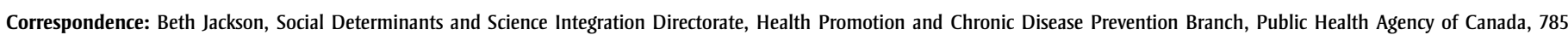
Carling Ave, Ottawa, ON K1A 0K9; Tel: 613-302-6791; Fax: 613-960-0921; Email: beth.jackson@phac-aspc.gc.ca 
growing urgency and better understanding of approaches to health that focus on social determinants and equity, another appeal for action was issued at the 2011 World Conference on Social Determinants of Health in Rio de Janeiro.

\section{Rio Political Declaration on Social Determinants of Health}

In May 2012, Canada and other United Nations Member States endorsed the Rio Political Declaration on Social Determinants of Health. ${ }^{11}$ The declaration expresses global political commitment for the implementation of a social determinants of health approach to reduce health inequities. Aiming to build international momentum for the development of dedicated national action plans and strategies, the Declaration identified five action areas critical to addressing health inequities:

- adopt better governance for health and development;

- promote participation in policy making and implementation;

- reorient the health sector towards reducing health inequities;

- strengthen global governance and collaboration; and

- monitor progress and increase accountability. ${ }^{11}$

\section{Canadian collaboration and action}

\section{The Chief Public Health Officer's Report}

Addressing both health equity and the determinants of health, the Chief Public Health Officer's (CPHO) inaugural report ${ }^{2}$ identified several priority areas and ways to address health inequalities in Canada:

- social investments (particularly for families with children living in poverty and for early childhood development);

- community capacity to address social determinants of health and health equity;

- integrated policies and joint action across sectors and jurisdictions;

- knowledge infrastructure to assess the health of subpopulations and the efficacy, adaptability and scalability of interventions; and

- leadership within and beyond the health sector. $^{2}$

These priority areas remain relevant today as jurisdictions and sectors in Canada work together to address health inequities.
The Pan-Canadian Public Health Network The Pan-Canadian Public Health Network (PHN) is a network of individuals from many sectors and levels of government, who effectively work together to strengthen public health in Canada. The PHN includes academics, researchers, public servants, members of non-governmental organizations and health professionals and is governed by a council of federal/provincial/territorial government representatives including the $\mathrm{CPHO}$ and senior public health officials from all jurisdictions. In 2010, the PHN council endorsed a set of Indicators of Health Inequalities ${ }^{12}$ and recommended that the Public Health Agency of Canada (PHAC), the Canadian Institute for Health Information (CIHI) and Statistics Canada report on these indicators. This pan-Canadian initiative will provide baseline data on over 50 indicators of health outcomes (for both chronic and infectious diseases), health-related behaviours and social determinants of health inequalities (e.g. food security). These data will be stratified, where possible, by a wide range of variables related to identity and social location (including sex, socioeconomic status, Aboriginal identity, cultural and/or racial background, immigrant status, rural/urban residence and sexual orientation). Results from this initiative, expected in 2016, will provide new information to federal, provincial and territorial governments and civil society to support decision making, priority setting, development of effective interventions, and monitoring of health inequalities.

\section{The Canadian Council on Social Determinants of Health}

The Canadian Council on Social Determinants of Health (CCSDH) is a collaborative, multisectoral stakeholder group established by PHAC in 2005 (as the Canadian Reference Group) to support Canada's contribution to the WHO Commission on the Social Determinants of Health. Since then, its role has evolved in recognition of the importance of broad intersectoral engagement for effectively addressing health inequities. The current dual mandate of the $\mathrm{CCSDH}$ is to advise PHAC on implementing the Rio Political Declaration on Social Determinants of Health ${ }^{11}$ and to facilitate and leverage action on the social determinants of health and health inequalities in
Canada. CCSDH membership includes representatives from all levels of government, civil society, business, labour and academia and from among Aboriginal peoples; members have been selected for their expertise and experience in addressing the social determinants of health. The Council is cochaired by a PHAC representative appointed by the CPHO.

\section{From knowledge to action}

While substantial progress has been made in tracking health inequalities, such knowledge alone does not improve health. Advances in health equity require complementary interventions at multiple levels (behavioural, organizational and societal/ systemic) across different populations in different contexts. ${ }^{13}$

\section{Recent advances}

In the last five years, a range of programs, policies and projects on health equity and determinants of health have been implemented across Canada in various jurisdictions. Some of these actions are described in the Rio Political Declaration on Social Determinants of Health: A Snapshot of Canadian Actions 2015. ${ }^{14}$

In November 2015, the Canadian Institute for Health Information released a suite of products from its "Trends in IncomeRelated Health Inequalities in Canada,3 project. These products-including a technical report and an interactive online tool-examine changes in income-related health inequalities over the past decade. For 11 of 16 indicators (including both social determinants and health outcomes), the health gap between higher-income and lower-income groups did not change. However, for 3 indicators (smoking, hospitalization of adults for chronic obstructive pulmonary disease, and fair/poor self-rated mental health) the gap widened. While inequalities decreased for the remaining 2 indicators, this was the result of a "levelling down" effect, where health outcomes worsened among higher-income groups and remained the same in lower-income groups. This documentation of income-related trends in health inequalities makes an important contribution to Canadian evidence. 


\section{Future directions}

Two important advances in applied research are particularly interesting in terms of our equity series: implementation science and population health intervention research.

\section{Implementation science}

Implementation science is the study of methods that promote the integration of research findings and evidence into health care policy and practice. ${ }^{15}$ It addresses the challenges of implementation, applying advances from one area to another, and the scaling-up of interventions. Implementation science is informed by a range of research and practice disciplines, building on operations research, participatory action research, management science, quality improvement and impact evaluation.

Implementation science has been used to enhance equity in health in Canada and elsewhere. Participants in recent consultative meetings organized by the Alliance for Health Policy and Systems Research of the WHO, the United States Agency for International Development and the World Bank Group noted that implementation science should promote a culture of evidenceinformed learning, engage stakeholders and improve decisions on policies and programs to achieve better health outcomes. ${ }^{16}$

An excellent example of implementation science improving a health outcome was one that addressed housing and HIV. Evidence shows that the lack of adequate housing is a barrier to HIV treatment and follow-up and is associated with an increased risk of forward transmission. ${ }^{17}$ Housing assistance for people with HIV who were formerly homeless or inadequately housed was found to improve their outcomes. ${ }^{17}$ In fact, adequate housing is linked to improved health for a number of health conditions. ${ }^{18}$

Population health intervention research Population health intervention research (PHIR) is similar to implementation science in that it focusses on policies and programs (frequently outside the health sector) that have the potential to improve health equity and health at the population level. ${ }^{19}$ However, the objective of PHIR is broader: it generates knowledge about whether specific interventions work, how they work, for whom and under what circumstances. It is also concerned with how classes and programs of interventions affect health and health equity in populations. PHIR concentrates on population health interventions, recognizing unique features of these interventions and the unique combination of tools required to study them. With this knowledge, we are better equipped to design interventions that can be effective for different populations across geographies and circumstances, and better equipped to advance health equity.

The challenges of this type of research are substantial, however, given "the involvement of actors from diverse sectors, the multiplicity of interacting components, the unique characteristics of public health as a key delivery system, the need to take into account the influence of context on both intervention implementation and its effective mechanisms, and the specific ethical issues raised with population health interventions." 20

An excellent example of an upstream intervention that had significant effects on population health was the MINCOME social experiment, which aimed to alleviate poverty by providing residents of Dauphin, Manitoba with a guaranteed annual income (GAI). While the main objective of the original study (conducted from 1974-79) was to assess the impact of a GAI on the labour market, recent intervention research has focussed on the population health effects of the GAI. Results have shown that hospitalizations for accidents, injuries and mental health issues, as well as physician contact for mental health complaints, declined over the course of the experiment relative to a matched comparison group. Moreover, more adolescents involved in the experiment stayed on to complete high school, resulting in a variety of other health and social benefits that would have a significant impact over their life course. ${ }^{21}$

\section{Conclusion}

The goal of working on health equity and determinants of health is to improve the health of the population and to ensure that the conditions that support health are distributed fairly. Canada has been making important strides in measuring and monitoring health inequalities, strengthening data infrastructure, building open information systems, undertaking sophisticated analyses of health inequalities, as well as conducting and evaluating the effectiveness of interventions. These efforts are strengthening the capacity of public health and other sectors to tackle health inequities.

With the launch of a new health equity series this month, both the Canada Communicable Disease Report (CCDR) and the Health Promotion and Chronic Disease Prevention in Canada (HPCDP) welcome reports on applied research that assess strategies to mitigate inequity and improve health outcome while continuing to publish reports that track, monitor and analyze health inequities. The aim is to increase knowledge and capacity to act on social determinants, and rigorously evaluate our efforts to advance equity and improve health.

\section{Acknowledgements}

We wish to acknowledge all those who work in the area of health equity and social determinants of health.

\section{Conflict of interest}

None

\section{References}

1. Commission on Social Determinants of Health. Social determinants of health; key concepts [Internet]. Geneva (CH): World Health Organization; 2005 [cited 2015 Dec 2]. Available from: http://www.who.int/social_ determinants/thecommission/finalreport/ key_concepts/en/

2. Public Health Agency of Canada. The Chief Public Health Officer's report on the state of public health in Canada: addressing health inequalities [Internet]. Ottawa $(\mathrm{ON})$ : Public Health Agency of Canada; 2008 [cited 2015 Nov 30]. Report No.: HP2-10/2008E. Available from: http://www.phac-aspc.gc.ca/cphorsphcrespcacsp/2008/fr-rc/index-eng.php 
3. Canadian Institute for Health Information. Trends in income-related health inequalities in Canada: summary report [Internet]. Ottawa (ON): Canadian Institute for Health Information; 2015. Report No.: 978-1-77109404-7 [cited 2015 Nov 30]. Available from: https://www.cihi.ca/en/summary_report_ inequalities_2015_en.pdf

4. Lalonde M. A new perspective on the health of Canadians: a working document [Internet]. Ottawa (ON): Minister of Supply and Services Canada; 1974 [cited 2015 Nov 30]. Report No.: H31-1374. Available from: http://www. phac-aspc.gc.ca/ph-sp/pdf/perspect-eng.pdf

5. World Health Organization. International Conference on Primary Health Care; 1978 Sept 6-12; Alma-Ata, USSR [Internet] Geneva (CH): World Health Organization; United Nations Children's Fund; 1978 [cited 2015 Nov 30]. Available from: http://www. unicef.org/about/history/files/Alma_Ata_ conference_1978_report.pdf

6. Epp J. Achieving health for all: a framework for health promotion [Internet]. Ottawa (ON): Health and Welfare Canada; 1986 [cited 2015 Nov 30]. Available from: http://www. hc-sc.gc.ca/hcs-sss/pubs/system-regime/ 1986-frame-plan-promotion/index-eng.php

7. Ottawa Charter for Health Promotion. An International Conference on Health Promotion; 1986 Nov 17-21 [Internet]. Ottawa (ON); 1986 [cited 2015 Nov 30]. Available from http://www.phac-aspc.gc.ca/ph-sp/ docs/charter-chartre/pdf/charter.pdf

8. Evans RG, Barer ML, Marmor TR, editors. Why are some people healthy and others not? The determinants of health of populations. New York: Aldine de Gruyter; 1994. p. 27-64.

9. Federal, Provincial and Territorial Advisory Committee on Population Health. Strategies for population health: investing in the health of Canadians. Halifax (NS): Minister of Supply and Services Canada; 1994 [cited 2015 Nov 30]. Report No.: H39-316/1994E. Available from: http://publications.gc.ca/collections/ Collection/H88-3-30-2001/pdfs/other/strat_ e.pdf

10. Commission on Social Determinants of Health (CSDH). Closing the gap in a generation: health equity through action on the social determinants of health [Internet]. Geneva $(\mathrm{CH})$ : World Health Organization; 2008 [cited 2015 Nov 30]. Report No.: 978 924156370 3. Available from: http://apps. who.int/iris/bitstream/10665/43943/1/978924 1563703_eng.pdf
11. World Health Organization. Rio Political Declaration on Social Determinants of Health [Internet]. World Conference on Social Determinants of Health; 2011 Oct 19-21; Rio de Janeiro, Brazil. Geneva $(\mathrm{CH})$ : World Health Organization; [cited 2015 Nov 30]. Available from: http://www.who.int/sdhconference/ declaration/Rio_political_declaration.pdf

12. Population Health Promotion Expert Group Indicators of health inequalities [Internet]. Ottawa (ON): Pan-Canadian Public Health Network; 2010 [cited 2015 Nov 30]. Joint publication of the Healthy Living Issue Group and the Pan-Canadian Public Health Network. Available from: http://www.phn-rsp. ca/pubs/ihi-idps/pdf/Indicators-of-HealthInequalities-Report-PHPEG-Feb-2010-EN.pdf

13. Pawson R, Greenhalgh T, Harvey G, Walshe K. Realist review: a new method of systematic review designed for complex policy interventions. J Health Serv Res Policy. 2005;10 Suppl 1:21-34.

14. Public Health Agency of Canada. Rio Political Declaration on Social Determinants of Health: a snapshot of Canadian actions 2015 [Internet]. Ottawa (ON): Public Health Agency of Canada; 2015 [cited 2015 Nov 30]. Available from: http://www.healthycanadians.gc.ca/publications/science-researchsciences-recherches/rio/index-eng.php

15. Fogarty International Center. Implementation science information and resources [Internet]. Bethesda (MD): National Institutes of Health; [cited 2015 Nov 30]. Available from: http:// www.fic.nih.gov/researchtopics/pages/imple mentationscience.aspx

16. Alliance for Health Policy and Systems Research. Implementation research and delivery science mini-conference series [Internet]. Geneva (CH): World Health Organization; 2014 Sept 26 [cited 2015 Nov 30]. Available from: http://www.who.int/ alliance-hpsr/news/2014/irds_series/en/

17. Aidala AA, Wilson MG, Shubert V, et al. Housing status, medical care, and health outcomes among people living with HIV/AIDS: a systematic review. Am J Public Health. 2016;106(1):e1-e23. DOI: 10.2105/AJPH.2015. 302905

18. Thomson H, Thomas S, Sellstrom E, Petticrew M. Housing improvements for health and associated socio-economic outcomes. Cochrane Database Syst Rev. 2013 Feb 28 2:CD008657. DOI: 10.1002/14651858. CD008657.pub2
19. Hawe P, Di Ruggiero E, Cohen E. Frequently asked questions about population health intervention research [Internet]. Canadian J Public Health. 2012 [cited 2015 Nov 30]; 103(5):e468-71. Available from: http://journal. cpha.ca/index.php/cjph/article/viewFile/ $3376 / 2723$

20. Riley B, Harvey J, Di Ruggiero E, Potvin L. Building the field of population health intervention research: the development and use of an initial set of competencies. Preventive Medicine Reports [Internet]. 2015 [cited 2015 Nov 30]; 2: [4 p.]. Available from: http://dx.doi.org/10.1016/j.pmedr.2015.09.017

21. Forget EL. The town with no poverty: the health effects of a Canadian guaranteed annual income field experiment [Internet]. Can Public Policy. 2011;37(3):283. Available from: https://dx.doi.org/10.3138/cpp.37.3.283 